\title{
Clinical outcomes of surgical resection versus radiofrequency ablation in very-early- stage hepatocellular carcinoma: a propensity score matching analysis
}

\author{
Yuan-Chen $\mathrm{Li}^{1 \dagger}$, Ping-Hung Chen ${ }^{1 \dagger}$, Jen-Hao Yeh ${ }^{1,2,3}$, Pojen Hsiao 1,2,3, Gin-Ho Lo ${ }^{1,2,3}$, TaoQian Tan 1,2,3, \\ Pin-Nan Cheng ${ }^{8}$, Hung-Yu Lin ${ }^{1,5}$, Yaw-Sen Chen ${ }^{1,5}$, Kun-Chou Hsieh ${ }^{5^{*+}}$, Pei-Min Hsieh ${ }^{1,5+}$ and \\ Chih-Wen Lin $1,2,3,4,6,7^{*}+$
}

\begin{abstract}
Background: The detection rate of Barcelona Clinic Liver Cancer (BCLC) very-early-stage hepatocellular carcinoma (HCC) is increasing because of advances in surveillance and improved imaging technologies for high-risk populations. Surgical resection (SR) and radiofrequency ablation (RFA) are both first-line treatments for very-early-stage HCC, but the differences in clinical outcomes between patients treated with SR and RFA remain unclear. This study investigated the prognosis of SR and RFA for very-early-stage HCC patients with long-term follow-up.

Methods: This study was retrospectively collected data on the clinicopathological characteristics, overall survival (OS), and disease-free survival (DFS) of 188 very-early-stage HCC patients ( $\leq 2 \mathrm{~cm}$ single HCC). OS and DFS were analyzed using the Kaplan-Meier method and Cox regression analysis. Propensity score matching (PSM) analysis was performed.

Results: Of the 188 HCC patients, 103 received SR and 85 received RFA. The median follow-up time was 56 months. The SR group had significantly higher OS than the RFA group (10-year cumulative OS: 55.2\% and 31.3\% in the SR and RFA groups, respectively). No statistically significant difference was observed in DFS between the SR and RFA groups (10-year cumulative DFS: $45.9 \%$ and $32.6 \%$ in the SR and RFA groups, respectively). After PSM, the OS in the SR group remained significantly higher than that in the RFA group (10-year cumulative OS: $54.7 \%$ and $42.2 \%$ in the SR and RFA groups, respectively). No significant difference was observed in DFS between the SR and RFA groups (10-year cumulative DFS: $43.0 \%$ and $35.4 \%$ in the SR and RFA groups, respectively). Furthermore, in the multivariate Cox regression analysis, treatment type (hazard ratio (HR): $0.54,95 \%$ confidence interval $(\mathrm{Cl}): 0.31-0.95 ; P=0.032$ ) and total bilirubin
\end{abstract}

\footnotetext{
*Correspondence: hkcjoe@gmail.com; lincw66@gmail.com

${ }^{\dagger}$ Yuan-Chen Li and Ping-Hung Chen are contributed equally to this work

${ }^{\dagger}$ Kun-Chou Hsieh, Pei-Min Hsieh and Chih-Wen Lin are contributed equally to this work for Corresponding author

1 School of Medicine, College of Medicine, I-Shou University, Kaohsiung, Taiwan

${ }^{5}$ Department of Surgery, E-Da Hospital, I-Shou University, Kaohsiung,

Taiwan

Full list of author information is available at the end of the article
}

(C) The Author(s) 2021. Open Access This article is licensed under a Creative Commons Attribution 4.0 International License, which permits use, sharing, adaptation, distribution and reproduction in any medium or format, as long as you give appropriate credit to the original author(s) and the source, provide a link to the Creative Commons licence, and indicate if changes were made. The images or other third party material in this article are included in the article's Creative Commons licence, unless indicated otherwise in a credit line to the material. If material is not included in the article's Creative Commons licence and your intended use is not permitted by statutory regulation or exceeds the permitted use, you will need to obtain permission directly from the copyright holder. To view a copy of this licence, visit http://creativecommons.org/licenses/by/4.0/. The Creative Commons Public Domain Dedication waiver (http://creativeco mmons.org/publicdomain/zero/1.0/) applies to the data made available in this article, unless otherwise stated in a credit line to the data. 
(HR: 1.92; 95\% Cl: 1.09-3.41; $P=0.025$ ) were highly associated with OS. In addition, age (HR: $2.14,95 \%$ Cl: 1.36-3.36; $P=0.001)$ and cirrhosis (HR: 1.79; 95\% Cl: $1.11-2.89 ; P=0.018$ ) were strongly associated with DFS.

Conclusion: For patients with very-early-stage HCC, SR was associated with significantly higher OS rates than RFA. However, no significant difference was observed in DFS between the SR and RFA groups.

Keywords: Surgical procedures, Radiofrequency ablation, Very-early-stage hepatocellular carcinoma, Overall survival, Disease-free survival

\section{Introduction}

Hepatocellular carcinoma (HCC) is the fifth most common malignancy worldwide, and the third most common cause of cancer-related deaths [1]. Patients with Barcelona Clinic Liver Cancer (BCLC) veryearly-stage HCC (BCLC stage 0) have well-preserved liver function with a single tumor less than $2 \mathrm{~cm}$ [2-4]. The detection rate of very-early-stage HCC is increasing because of advances in surveillance technology for at-risk populations [5-7]. According to the American Association for the Study of Liver Disease (AASLD), the European Association for the Study of Liver (EASL), and the Asian Pacific Association for the Study of the Liver (APASL) guidelines, the currently recommended treatment options for very-early-stage HCC are surgical resection (SR), radiofrequency ablation (RFA), and liver transplantation [2-4]. Because of the organ shortage, SR and RFA are the most common treatments for very-early-stage HCC patients $[8,9]$.

It is still debated whether SR or RFA is more effective for treating very-early-stage HCC. Many previous studies have demonstrated that RFA is as effective for treating small liver tumors as SR [10-18]. Another study reported that RFA may be the first choice for patients with BCLC stage 0 HCC [19]. However, recent studies have demonstrated that SR is associated with higher overall survival (OS) and disease-free survival (DFS) rates compared with RFA in HCC patients with a single small HCC [12, 20-25]. Conflicting information still arises because of the lack of long-term survival and recurrence rate data. Therefore, we designed a retrospective study to compare the long-term survival and recurrence rates associated with SR and RFA. Furthermore, propensity score matching was used to minimize the effects of confounding factors.

\section{Methods}

Data from 4092 HCC patients at E-Da Hospital, I-Shou University, Kaohsiung, Taiwan from 2007 to 2018 were retrospectively collected. However, 3780 patients were excluded because they had BCLC stage A, B, C, and D HCC, and 124 patients were excluded because they were receiving treatments other than SR and RFA or had incomplete data. Therefore, this prospective study enrolled 188 HCC patients who received only SR or RFA treatment (Fig. 1). Our study was approved by the Institutional Review Board of E-Da Hospital. HCC diagnosis was based on the criteria of the practice guidelines of the EASL or AASLD [2, 3].

Clinicopathological parameters included the following demographic data: sex and age, body mass index (BMI), excessive alcohol use, infection with hepatitis $B$ virus (HBV) infection and hepatitis $\mathrm{C}$ virus (HCV), tumor size, liver function, mortality, recurrence, and follow-up time. Tumor size and liver cirrhosis were diagnosed and evaluated through histopathologic and radiological findings, namely computed tomography (CT) or magnetic resonance imaging (MRI) findings with non-specific gadolinium and EOB-MRI. The liver function data were primarily measured using a hematology test and assessed using Child-Pugh (CP) scores.

\section{HCC treatment}

Patients were treated with SR or RFA; our multidisciplinary team selected a suitable therapy after considering the patient's preference and the medical evidence. Patients who received SR were evaluated according to the subsequent remnant liver volume, with consideration of tumor-free resection margins and hepatic functional reserves [26]. The RFA endpoint was the complete ablation of both the visible tumor and tumor margins. Patients were followed up every 3 to 6 months with abdominal ultrasound and CT or MRI, and alpha-fetoprotein (AFP) levels were assessed. OS was defined as the time from the date of diagnosis to the date of death or last visit. DFS was defined as the time from the date of diagnosis to the date of $\mathrm{HCC}$ recurrence or last visit. The last follow-up date was in August 2018.

\section{Data analysis and statistics}

All statistical analyses were performed using SPSS ver. 23.0 (SPSS, Chicago, IL, USA). Numerical data are expressed as medians and ranges, and categorical data are described using numbers and percentages. OS and DFS were determined using the Kaplan-Meier method and compared between patients receiving different treatments. Cox proportional hazards regression analysis of OS and DFS was also performed. Furthermore, we used 


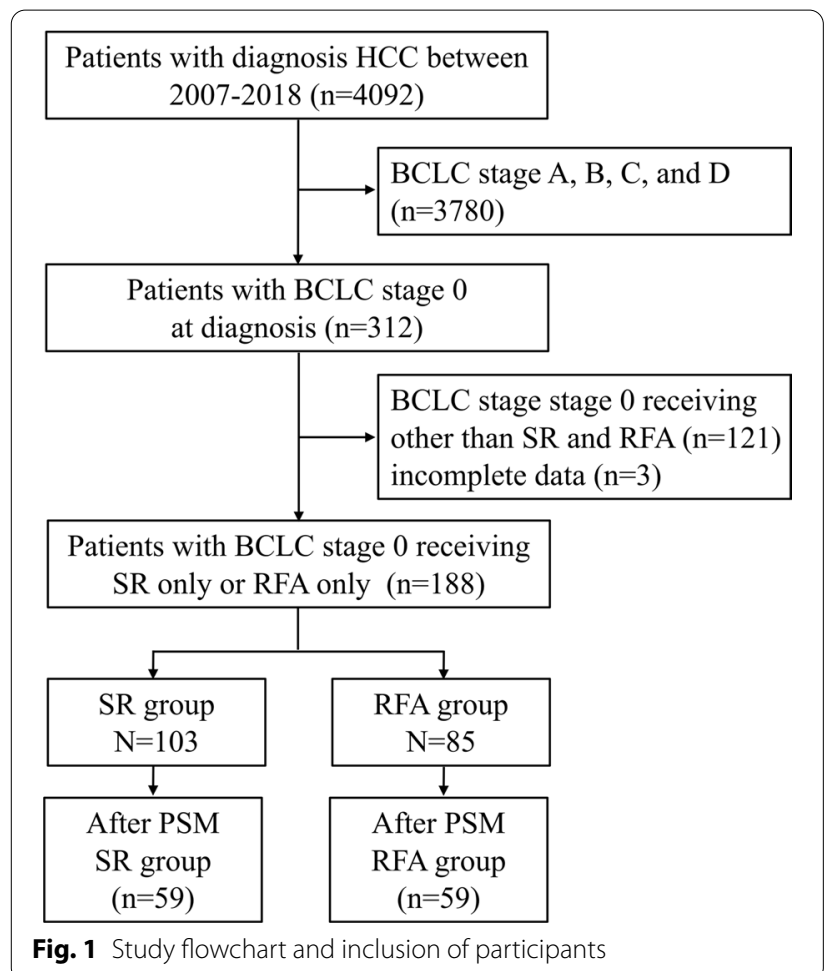

logistic regression to generate propensity score matching (PSM) with age, sex, tumor size, cirrhosis, total bilirubin, albumin, and AFP level to reduce bias in our analyses. The two treatment groups were matched with the control group according to PSM using a caliper width of 0.02 . After PSM, the baseline covariates were compared using the paired $t$ test or Mann-Whitney $\mathrm{U}$ test for continuous variables and the chi-square test for categorical variables. A $p$ value of $<0.05$ indicated statistical significance.

\section{Results}

\section{Patient characteristics}

The demographic data of patients with BCLC veryearly-stage HCC are summarized in Table 1 . Of the 188 patients, 103 received SR and 85 received RFA. The median follow-up time was 56 months (range: 6-142 months). Patients were significantly younger in the SR group than in the RFA group. The liver function, including total bilirubin, albumin, international normalized ratio (INR), and albumin-bilirubin (ALBI) grade, was lower in the RFA group. In the entire cohort, $45.7 \%$ of patients were $\mathrm{HBV}$ positive, and $48.4 \%$ were $\mathrm{HCV}$ positive. No significant difference was observed in the number of HBV-positive and HCV-positive patients between the SR group and the RFA group. The rate of cirrhosis was significantly higher in the RFA group than in the SR group.

\section{Overall survival and disease-free survival}

\section{before propensity score matching}

In total, 28 and 41 patients died in the SR group and the RFA group, respectively. OS was significantly higher in the SR group than in the RFA group $(P<0.001)$ (Fig. 2A). The 1-, 3-, 5-, and 10-year cumulative OS rates were $99.0 \%, 87.6 \%, 80.0 \%$, and $55.2 \%$ in the SR group and $91.7 \%, 72.8 \%, 56.7 \%$, and $31.3 \%$ in the RFA group, respectively. In addition, 43 and 36 patients experienced HCC recurrence in the SR and RFA groups, respectively. No statistically significant difference in DFS was observed between the SR and RFA groups (Fig. 2b). The 1-, 3-, 5-, and 10-year cumulative DFS rates were $90.2 \%, 72.0 \%$, $59.3 \%$, and $45.9 \%$ in the SR group and $86.6 \%, 59.8 \%$, $49.8 \%$, and $32.6 \%$ in the RFA group, respectively.

\section{Overall survival and disease-free survival after propensity score matching}

After PSM, the total number of patients was 116, with 58 patients in the SR group and 58 patients in the RFA group. None of the clinical features were significantly different between the SR and RFA groups (Table 1). A total of 18 and 27 patients died in the SR and RFA groups, respectively. OS was significantly higher in the SR group than in the RFA group $(P=0.03)$ (Fig. 3a). The 1-, 3-, $5-$, and 10-year cumulative OS rates were $98.2 \%, 88.8 \%$, $77.7 \%$, and $54.7 \%$ in the SR group and $91.4 \%, 77.2 \%$, $60.1 \%$, and $42.2 \%$ in the RFA group, respectively. Furthermore, 25 and 24 patients experienced HCC recurrence in the SR and RFA groups, respectively. No statistically significant difference in DFS was observed between the SR and RFA groups (Fig. 3b). The 1-, 3-, 5-, and 10-year cumulative DFS rates were $93.0 \%, 71.7 \%, 57.1 \%$, and $43.0 \%$ in the SR group and $91.2 \%, 62.0 \%, 53.2 \%$, and $35.4 \%$ in the RFA group, respectively.

\section{Prognostic factors associated with overall survival and disease-free survival}

Treatment type, CP class A, cirrhosis, ascites, serum total bilirubin, serum albumin, ALBI grade, and serum AFP were strongly associated with OS in the univariate analysis (Table 2). The multivariate Cox regression analysis revealed that the treatment type (hazard ratio (HR): $1.75,95 \%$ confidence interval $(\mathrm{CI}): 1.08-3.11 ; P=0.046)$, serum total bilirubin (HR: 0.52; 95\% CI: $0.28-0.95$; $P=0.034$ ), and tumor recurrence (HR: 0.46 ; $95 \% \mathrm{CI}$ : $0.28-0.78 ; P=0.006)$ were strongly associated with OS (Table 2). The effect of SR was better OS than RFA in the almost subgroups (Fig. 4a).

Age and cirrhosis were strongly associated with DFS in the univariate analysis (Table 3). The multivariate Cox regression analysis revealed that age (HR: $0.47,95 \% \mathrm{CI}$ : $0.30-0.73 ; P=0.001$ ) and cirrhosis (HR: $0.56 ; 95 \% \mathrm{CI}$ : 
Table 1 Clinical characteristics of BCLC very-early stage hepatocellular carcinoma patients before and after propensity scores matching

\begin{tabular}{|c|c|c|c|c|c|c|c|c|}
\hline \multirow[t]{2}{*}{ Characteristics } & \multicolumn{4}{|c|}{ Study population before PSM } & \multicolumn{4}{|c|}{ Study population after PSM } \\
\hline & Total & SR group & RFA group & $P$-value & Total & SR group & RFA group & $P$-value \\
\hline Patients & 188 & 103 & 85 & & 116 & 58 & 58 & \\
\hline Age, years & $59(23-82)$ & $57(23-82)$ & $62(34-81)$ & 0.006 & $61(34-82)$ & $61(35-82)$ & $61(34-80)$ & 0.788 \\
\hline \multicolumn{9}{|l|}{ Sex } \\
\hline Male & 130(69.1) & $75(72.8)$ & $55(64.7)$ & 0.299 & $78(67.2)$ & $39(67.2)$ & $39(67.2)$ & 1 \\
\hline Female & $58(30.9)$ & $28(27.2)$ & $30(35.3)$ & & $38(32.8)$ & $19(32.8)$ & $19(32.8)$ & \\
\hline \multicolumn{9}{|l|}{$B M I$} \\
\hline$\leqq 24 \mathrm{~kg} / \mathrm{m}^{2}$ & $93(49.5)$ & $50(48.5)$ & $43(50.6)$ & 0.895 & $59(50.9)$ & $29(50.0)$ & $30(51.7)$ & 1 \\
\hline$>24 \mathrm{~kg} / \mathrm{m}^{2}$ & $95(50.5)$ & $53(51.5)$ & $42(49.4)$ & & $57(49.1)$ & $29(50.0)$ & $28(48.3)$ & \\
\hline Alcohol use & $53(28.2)$ & $25(24.33)$ & $28(32.9)$ & 0.249 & $32(27.6)$ & $15(25.9)$ & $17(29.3)$ & 0.835 \\
\hline \multicolumn{9}{|l|}{$H B V$} \\
\hline Positive & $86(45.7)$ & $51(49.5)$ & $35(41.2)$ & 0.320 & $51(44.0)$ & $28(48.3)$ & $23(39.7)$ & 0.454 \\
\hline Negative & $102(54.3)$ & $52(50.5)$ & $50(58.8)$ & & $65(56.0)$ & $30(51.7)$ & $35(60.3)$ & \\
\hline \multicolumn{9}{|l|}{$\mathrm{HCV}$} \\
\hline Positive & $91(48.4)$ & $49(47.6)$ & $42(49.4)$ & 0.917 & $61(52.6)$ & $34(58.6)$ & $27(46.6)$ & 0.265 \\
\hline Negative & $97(51.6)$ & $54(52.4)$ & $43(50.6)$ & & $55(47.4)$ & $24(41.4)$ & $31(53.4)$ & \\
\hline Child-Pugh class A & $179(95.2)$ & $100(97.1)$ & 79 (92.9) & 0.326 & $113(97.4)$ & $56(96.6)$ & 57(98.3) & 1 \\
\hline Cirrhosis & $115(61.2)$ & $54(52.4)$ & $61(71.8)$ & 0.011 & $72(62.1)$ & $36(62.1)$ & $36(62.1)$ & 1 \\
\hline Ascites & $13(6.9)$ & $6(5.8)$ & $7(8.2)$ & 0.719 & $8(6.9)$ & $4(6.9)$ & $4(6.9)$ & 1 \\
\hline INR & $1.0(0.9-1.7)$ & $1.0(0.9-1.3)$ & $1.1(0.9-1.7)$ & $<0.001$ & $1.0(0.9-1.7)$ & $1.0(0.9-1.3)$ & $1.0(0.9-1.7)$ & 0.382 \\
\hline Total bilirubin, mg/dL & $0.9(0.2-5.4)$ & $0.8(0.2-5.4)$ & $1.1(0.3-4.2)$ & 0.001 & $1.0(0.3-3.9)$ & $0.8(0.5-3.9)$ & $1.1(0.3-4.2)$ & 0.785 \\
\hline Albumin, $\mathrm{g} / \mathrm{dL}$ & $4.1(2.5-4.9)$ & $4.2(3.2-4.9)$ & $4.0(2.5-4.7)$ & $<0.001$ & $4.1(2.6-4.9)$ & $4.1(3.2-4.9)$ & $4.0(2.6-4.6)$ & 0.051 \\
\hline ALBI grade 1 & $166(88.3)$ & $97(94.2)$ & $69(81.2)$ & 0.011 & $102(87.9)$ & $53(91.4)$ & $49(84.5)$ & 0.393 \\
\hline AFP $>200 \mathrm{ng} / \mathrm{ml}$ & $29(15.4)$ & $12(11.7)$ & $17(20.0)$ & 0.169 & $17(14.7)$ & $5(8.6)$ & $12(20.7)$ & 0.115 \\
\hline Tumor size, cm & $1.8(1.0-2.0)$ & $1.8(1.0-2.0)$ & $1.8(1.0-2.0)$ & 0.127 & $1.8(1.0-2.0)$ & $1.9(1.0-2.0)$ & $1.8(1.0-2.0)$ & 0.875 \\
\hline Mortality & 69 (36.7) & $28(27.2)$ & $41(48.2)$ & 0.005 & 44 (37.9) & $17(29.3)$ & 27 (46.6) & 0.085 \\
\hline Recurrence & $79(42.0)$ & $43(41.7)$ & $36(42.4)$ & 1.000 & $49(42.2)$ & $25(43.1)$ & $24(41.4)$ & 1.000 \\
\hline
\end{tabular}

Data shown as median (range) or number (\%); PSM: propensity score matching; SR: Surgical resection; RFA: Radiofrequency ablation; BMI: Body mass index; HBV: Hepatitis B virus; HCV: Hepatitis C virus; INR: international normalized ratio; ALBI: Albumin- bilirubin; AFP: Alpha-fetoprotein;

$0.35-0.90 ; P=0.018)$ were strongly associated with DFS (Table 3). The effect of SR was similar DFS with RFA in all subgroups (Fig. 4b).

\section{Discussion}

In our study, SR provided better OS than RFA, both before and after propensity score matching. In patients with BCLC very-early-stage HCC, the 10-year cumulative OS rates were $55.2 \%$ and $31.3 \%$ in the SR and RFA groups, respectively $(P<0.001)$. Furthermore, no significant differences in DFS were observed between the SR and RFA groups. The 10-year cumulative OS rates were $45.9 \%$ and $32.6 \%$ in the SR and RFA group, respectively. The risk factors identified for OS were the treatment type and tumor size, and the risk factors identified for DFS were age and cirrhosis.
Our study also demonstrated that the SR group had higher OS than the RFA group, whereas no significant difference in DFS was observed between the SR and RFA groups. These results are different from those of several previous studies, which have reported that patients with small HCC who received SR had higher OS and DFS than those who received RFA [20-25]. Furthermore, our study results conflict with those from a previous study showing that SR resulted in higher DFS, but not OS, compared with RFA [12]. By contrast, our study observed that RFA resulted in similar DFS but lower OS compared with SR. Our results were also different from a previous study that reported higher OS and DFS for RFA than for SR. Many studies have demonstrated that OS and DFS are similar for patients treated with RFA and SR [10, 11, 13-17, 22, $27,28]$. In addition, our results were different from those of a previous study showing that RFA resulted in higher OS and similar DFS compared with SR [19]. 


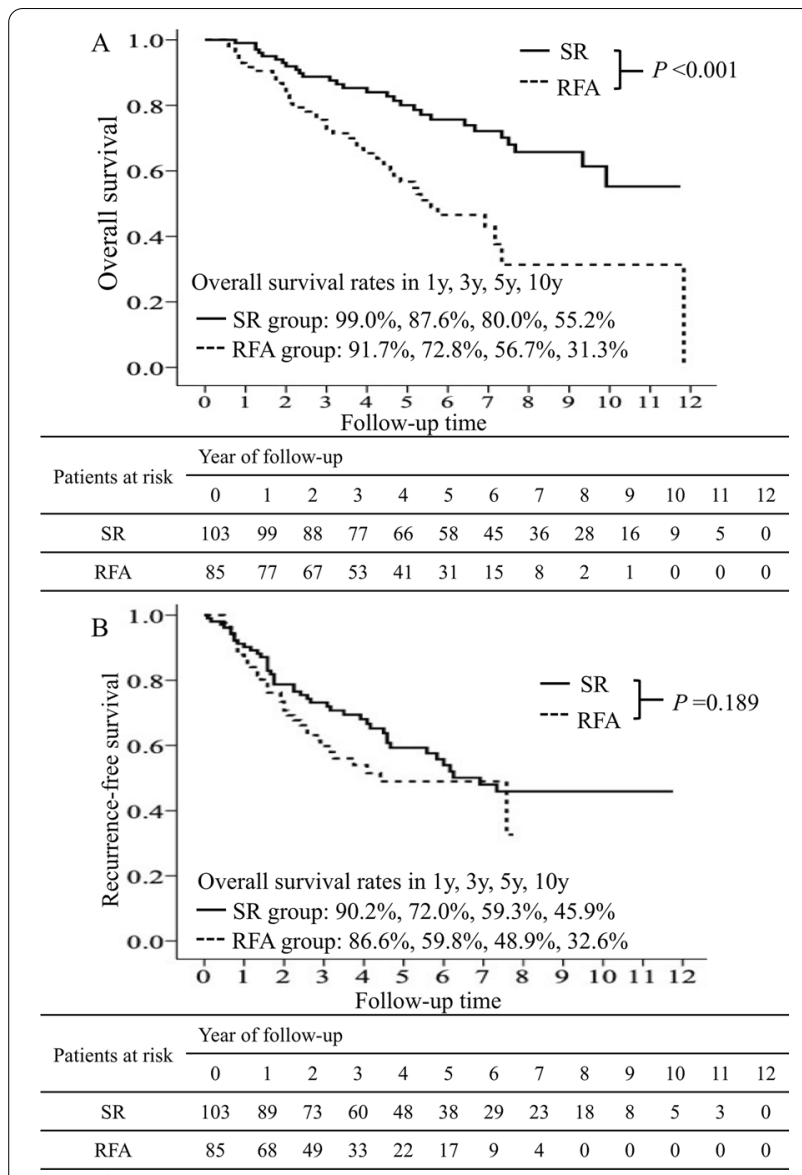

Fig. 2 Overall survival and disease-free survival for different treatments in patients with Barcelona Clinic Liver Cancer stage 0 hepatocellular carcinoma. The cumulative incidence of overall survival (A) and disease-free survival (B) for different treatments. Surgical resection (SR) resulted in significantly higher overall survival rates than radiofrequency ablation (RFA) $(P<0.001)(\mathbf{A})$. No significant difference was observed in disease-free survival between SR and RFA (B)

Our study showed that RFA, lower liver function (i.e., lower serum albumin, higher bilirubin, and lower ALBI grade), and the presence of cirrhosis or ascites were significantly associated with lower OS rates according to the univariate analysis. These factors have been identified by previous studies [18, 29]. Furthermore, older age and the presence of cirrhosis were significantly associated with lower DFS rates, which supports the results of a multicenter Italian survey [27]. However, a nationwide cohort in Japan demonstrated that older patients may receive RFA rather than SR because of the presence of comorbidities [30]. Therefore, the treatment type may impact the results of recurrence. Although patients receiving RFA in our study were older than those receiving SR, we did not identify an association between treatment type and recurrence rates.

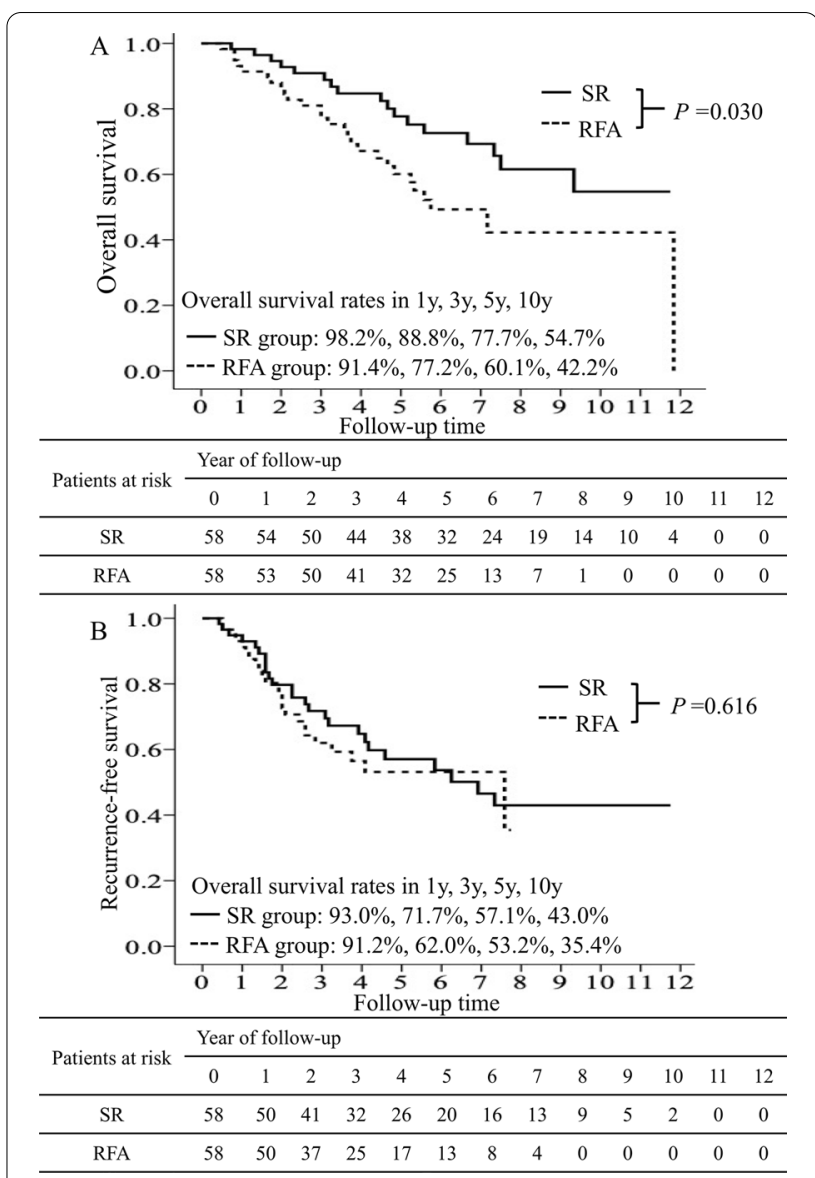

Fig. 3 Overall survival and disease-free survival for different treatments after propensity score matching. The cumulative incidence of overall survival (A) and disease-free survival (B) for different treatments after propensity score matching. Overall survival remained significantly higher in surgical resection (SR) than in radiofrequency ablation (RFA) $(P<0.001)(\mathbf{A})$. No significant difference was observed in disease-free survival between SR and RFA (B)

Previous studies showed that median post-recurrence OS after SR was 26 months [31] and median post-recurrence OS after RFA was 22 months [32]. Our study demonstrated that median post-recurrence OS after SR and RFA was 34 and 32 months, respectively. Our results were better OS post-recurrence after SR and RFA treatment. Furthermore, there is currently no standard of care for adjuvant therapy in HCC after curative treatments because evidence is limited in HCC patients after potentially curative treatment [33-35].

Conventional transcatheter arterial chemoembolization (cTACE) was an optional treatment for HCC and doxorubicin-loaded drug-eluting beads TACE (DEBTACE) has been developed to maximize the therapeutic efficacy of cTACE for HCC. DEB-TACE was more cost-effective than conventional TACE when a minimum willingness-to-pay was accepted, mainly 
Table 2 Univariable and multivariable Cox-proportional hazard model for overall survival in BCLC very-early stage hepatocellular carcinoma patients

\begin{tabular}{|c|c|c|c|c|}
\hline \multirow[t]{2}{*}{ Characteristics } & \multicolumn{2}{|c|}{ Univariate Cox regression analyses } & \multicolumn{2}{|c|}{ Multivariate Cox regression analyses } \\
\hline & Unadjusted HR (95\% Cl) & $P$-value & Adjusted HR (95\% Cl) & $P$-value \\
\hline Treatment type (SR vs. RFA) & $2.58(1.56-4.25)$ & $<0.001$ & $1.75(1.08-3.11)$ & 0.046 \\
\hline Male & $1.20(0.71-2.04)$ & 0.501 & & \\
\hline Age ( $\geq 60 y$ vs, <60y) & $0.74(0.46-1.19)$ & 0.219 & & \\
\hline BMI $(\geq 24$ kg/m² vs. $<24$ kg/m²) & $1.06(0.66-1.71)$ & 0.808 & & \\
\hline Alcohol use & $0.71(0.43-1.19)$ & 0.196 & & \\
\hline HBV & $1.58(0.96-2.59)$ & 0.073 & & \\
\hline $\mathrm{HCV}$ & $0.74(0.46-1.19)$ & 0.212 & & \\
\hline Child-Pugh class A & $2.60(1.19-5.70)$ & 0.017 & $1.21(0.46-3.17)$ & 0.697 \\
\hline Cirrhosis & $0.52(0.31-0.88)$ & 0.015 & $0.90(0.50-1.60)$ & 0.709 \\
\hline Ascites & $0.39(0.20-0.76)$ & 0.006 & $0.56(0.28-1.13)$ & 0.104 \\
\hline Total bilirubin ( $\geq 1.3 \mathrm{mg} / \mathrm{dL}$ vs. $<1.3 \mathrm{mg} / \mathrm{dL}$ ) & $0.33(0.20-0.54)$ & $<0.001$ & $0.52(0.28-0.95)$ & 0.034 \\
\hline Albumin ( $\geq 3.5 \mathrm{~g} / \mathrm{dL}$ vs. $<3.5 \mathrm{~g} / \mathrm{dL})$ & $2.55(1.33-4.87)$ & 0.005 & $1.59(0.74-3.38)$ & 0.232 \\
\hline ALBl grade 1 vs. 2/3 & $1.91(1.04-3.52)$ & 0.036 & $1.10(0.52-2.35)$ & 0.798 \\
\hline $\operatorname{AFP}(\geq 200 \mathrm{ng} / \mathrm{ml} \mathrm{vs} .<200 \mathrm{ng} / \mathrm{ml})$ & $0.56(0.31-1.00)$ & 0.051 & & \\
\hline Tumor size $(\geq 1.8 \mathrm{~cm}$ vs. $<1.8 \mathrm{~cm})$ & $0.68(0.41-1.13)$ & 0.137 & & \\
\hline Tumor recurrence & $0.45(0.28-0.74)$ & 0.002 & $0.46(0.28-0.78)$ & 0.006 \\
\hline
\end{tabular}

Cl: Conference Incidence; SR: Surgical resection; BMI: Body mass index; HBV: Hepatitis B virus; HCV: Hepatitis C virus; ALBI: Albumin- bilirubin; AFP: Alpha-fetoprotein;

depending on shorter in-hospital stay and better quality of life [36]. Moreover, it is an important issue to explore the economic impact between SR and RFA treatment in very-early stage HCC. RFA had similar life-expectancy and quality-adjusted life-expectancy at a lower cost than SR and was the most cost-effective therapeutic strategy for very-early stage HCC patients in a 10-year perspective [22]. However, SR remains the best strategy to adopt as a result of better OS at an acceptable increase in cost.

This study has several limitations. First, it is a retrospective study and is thus highly vulnerable to

Table 3 Univariable and multivariable Cox-proportional hazard model for disease-free survival in BCLC very-early stage hepatocellular carcinoma patients

\begin{tabular}{|c|c|c|c|c|}
\hline \multirow[t]{2}{*}{ Characteristics } & \multicolumn{2}{|c|}{ Univariate Cox regression analyses } & \multicolumn{2}{|c|}{ Multivariate Cox regression analyses } \\
\hline & Unadjusted HR (95\% Cl) & $P$-value & Adjusted HR (95\% Cl) & $P$-value \\
\hline Treatment type (SR vs. RFA) & $1.35(0.86-2.11)$ & 0.193 & & \\
\hline Male & $0.97(0.60-1.56)$ & 0.903 & & \\
\hline Age $(\geq 60 y$ vs, $<60 y)$ & $0.49(0.31-0.76)$ & 0.002 & $0.47(0.30-0.73)$ & 0.001 \\
\hline $\mathrm{BMI}\left(\geq 24 \mathrm{~kg} / \mathrm{m}^{2} \mathrm{vs} .<24 \mathrm{~kg} / \mathrm{m}^{2}\right)$ & $1.29(0.83-2.02)$ & 0.256 & & \\
\hline Alcohol use & $1.04(0.63-1.72)$ & 0.871 & & \\
\hline HBV & $1.29(0.83-2.03)$ & 0.256 & & \\
\hline $\mathrm{HCV}$ & $0.73(0.47-1.14)$ & 0.164 & & \\
\hline Child-Pugh class A & $1.14(0.42-3.13)$ & 0.795 & & \\
\hline Cirrhosis & $0.59(0.37-0.96)$ & 0.032 & $0.56(0.35-0.90)$ & 0.018 \\
\hline Ascites & $0.76(0.35-1.65)$ & 0.482 & & \\
\hline Total bilirubin ( $\geq 1.3 \mathrm{mg} / \mathrm{dL}$ vs. $<1.3 \mathrm{mg} / \mathrm{dL}$ ) & $0.87(0.52-1.47)$ & 0.609 & & \\
\hline Albumin ( $\geq 3.5 \mathrm{~g} / \mathrm{dL}$ vs. $<3.5 \mathrm{~g} / \mathrm{dL})$ & $1.08(0.50-2.36)$ & 0.840 & & \\
\hline ALBI grade 1 vs. $2 / 3$ & $0.82(0.39-1.70)$ & 0.589 & & \\
\hline $\operatorname{AFP}(\geq 200 \mathrm{ng} / \mathrm{ml}$ vs. $<200 \mathrm{ng} / \mathrm{ml})$ & $0.78(0.44-1.40)$ & 0.406 & & \\
\hline Tumor size $(\geq 1.8 \mathrm{~cm}$ vs. $<1.8 \mathrm{~cm})$ & $1.19(0.75-1.87)$ & 0.467 & & \\
\hline
\end{tabular}

Cl: Conference Incidence; SR: Surgical resection; BMI: Body mass index; HBV: Hepatitis B virus; HCV: Hepatitis C virus; ALBI: Albumin- bilirubin; AFP: Alpha-fetoprotein 


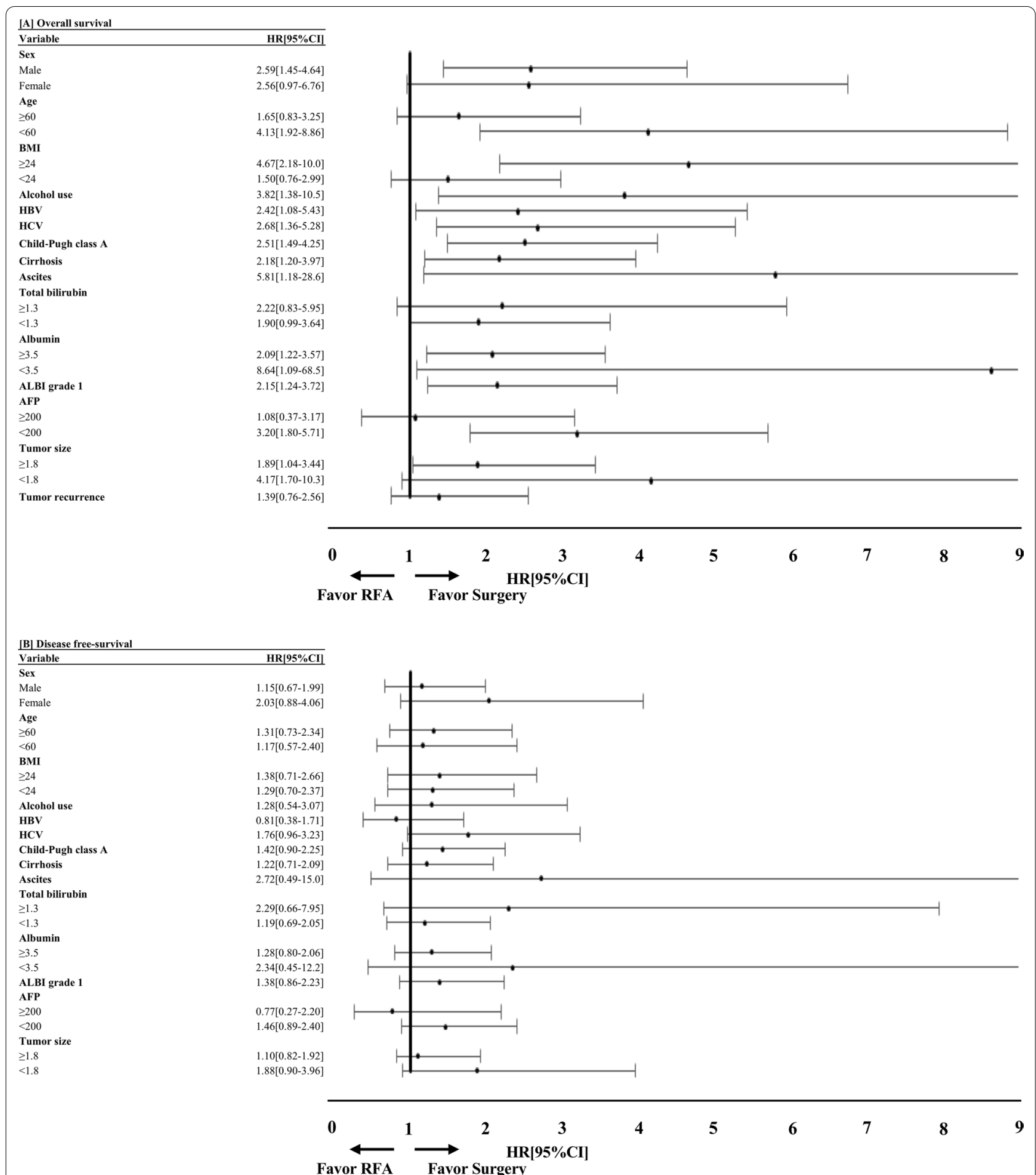

Fig. 4 Forest plot of the treatment effect on overall survival and recurrence-free survival in subgroup analyses. The effect of surgical resection (SR) was better overall survival than radiofrequency ablation (RFA) in the almost subgroups (A). The effect of SR was similar DFS with RFA in all subgroups (B) 
potential bias; even after propensity score matching, some confounding factors are unavoidable. The best solution to mitigate this bias is to conduct a randomized controlled trial. However, randomization is difficult because the treatment decision must consider the patients' physical conditions, presenting ethical concerns. Second, the relatively low number of patients may lead to type I error, which influences the results of univariate analyses. The limited number of certain events also made it difficult to perform robust multivariate analyses. Therefore, the results of the multivariate analyses require validation in a cohort with a larger sample size and a greater number of events.

\section{Conclusions}

SR was associated with a superior OS rate than RFA. However, no significant difference was observed in the DFS rate between the SR and RFA groups. The risk factors identified for OS were treatment type and serum total bilirubin, and the risk factors for DFS were age and cirrhosis.

\section{Abbreviations}

HCC: Hepatocellular carcinoma; BCLC: Barcelona Clinic Liver Cancer; AASLD: American Association for the Study of Liver Disease; ESAS: European Association for the Study of Liver; APASL: Asian Pacific Association for the Study of the Liver; SR: Surgical resection; RFA: Radiofrequency ablation; OS: Overall survival; DFS: Disease-free survival; CP score: Child-Pugh score; HBV: Hepatitis B virus; HCV: Hepatitis C virus; PSM: Propensity score matching; HR: Hazard ratio; Cl: Confidence interval; ECOG: Eastern Cooperative Oncology Group.

\section{Acknowledgements}

Not applicable.

\section{Authors' contributions}

YCL, PHC, and JHY: study concept and design, acquisition of data, analysis and interpretation of data, and drafting of the manuscript. PH, GHL, TT, PNC, HYL, YSC, KCH, and PMY: study concept and design; critical revision of the manuscript for important intellectual content; and administrative, technical, or material support. CWL: study concept and design; analysis and interpretation of data; critical revision of the manuscript for important intellectual content; administrative, technical, or material support; and study supervision. All authors approved of the final version of the manuscript.

\section{Funding}

This study was supported by grants from the Ministry of Science and Technology (MOST) (108-2314-B-214-006-MY2, 109-2811-B-214-500, and 110-2314-B-214-004-MY1); NCKUEDA10803 and NCKUEDA10916; and E-Da Hospital (EDAHS109004, EDAHS109005, EDAHP108036, EDAHP108037, EDAHP108038, EDAHP110035, EDAHP1 10036, EDAHP110037, and EDAHP1 10040) to Chih-Wen Lin.

\section{Availability of data and materials}

Data is available from the corresponding author upon reasonable request.

\section{Declarations}

Ethics approval and consent to participate

The study was conducted in accordance with the guidelines of the International Conference on Harmonization for Good Clinical Practice and was approved by the Ethics Committee of E-Da Hospital, I-Shou University (EMRP-109-135 and 136). Participants signed informed consent for study participation.

\section{Consent for publication}

Not applicable.

\section{Competing interests}

None of the authors have commercial affiliations that constitute any conflict of interest.

\section{Author details}

${ }^{1}$ School of Medicine, College of Medicine, I-Shou University, Kaohsiung, Taiwan. ${ }^{2}$ Division of Gastroenterology and Hepatology, Department of Medicine, E-Da Hospital, I-Shou University, No. 1, Yida Road, Jiaosu Village, Yanchao District, Kaohsiung City 82445, Taiwan. ${ }^{3}$ Division of Gastroenterology and Hepatology, I-Shou University, E-Da Dachang Hospital, Kaohsiung, Taiwan. ${ }^{4}$ Health Examination Center, E-Da Hospital, I-Shou University, Kaohsiung, Taiwan.

${ }^{5}$ Department of Surgery, E-Da Hospital, I-Shou University, Kaohsiung, Taiwan. ${ }^{6}$ School of Chinese Medicine, College of Chinese Medicine, China Medical University, Taichung, Taiwan. ${ }^{7}$ Research Center for Traditional Chinese Medicine, China Medical University Hospital, Taichung, Taiwan. ${ }^{8}$ Division of Gastroenterology and Hepatology, Department of Internal Medicine, College of Medicine, National Cheng Kung University Hospital, National Cheng Kung University, Tainan, Taiwan.

Received: 3 October 2021 Accepted: 28 October 2021

Published online: 08 November 2021

\section{References}

1. Bertuccio P, Turati F, Carioli G, Rodriguez T, La Vecchia C, Malvezzi M, et al. Global trends and predictions in hepatocellular carcinoma mortality. J Hepatol. 2017:67(2):302-9.

2. Heimbach JK, Kulik LM, Finn RS, Sirlin CB, Abecassis MM, Roberts LR, et al. AASLD guidelines for the treatment of hepatocellular carcinoma. Hepatology. 2018;67(1):358-80

3. European Association for the Study of the Liver. Electronic address EEE, European Association for the Study of the L EASL Clinical Practice Guidelines: management of hepatocellular carcinoma. J Hepatol. 2018;69(1):182-236.

4. Omata M, Cheng AL, Kokudo N, Kudo M, Lee JM, Jia J, et al. Asia-Pacific clinical practice guidelines on the management of hepatocellular carcinoma: a 2017 update. Hepatol Int. 2017;11(4):317-70.

5. Santi V, Trevisani F, Gramenzi A, Grignaschi A, Mirici-Cappa F, Del Poggio $P$, et al. Semiannual surveillance is superior to annual surveillance for the detection of early hepatocellular carcinoma and patient survival. J Hepatol. 2010;53(2):291-7.

6. Golfieri R, Garzillo G, Ascanio S. Renzulli M Focal lesions in the cirrhotic liver: their pivotal role in gadoxetic acid-enhanced MRI and recognition by the Western guidelines. Dig Dis. 2014;32(6):696-704.

7. Renzulli M, Golfieri R. Bologna Liver Oncology G Proposal of a new diagnostic algorithm for hepatocellular carcinoma based on the Japanese guidelines but adapted to the Western world for patients under surveillance for chronic liver disease. J Gastroenterol Hepatol. 2016;31(1):69-80.

8. Mazzaferro V, Regalia E, Doci R, Andreola S, Pulvirenti A, Bozzetti F, et al. Liver transplantation for the treatment of small hepatocellular carcinomas in patients with cirrhosis. N Engl J Med. 1996;334(11):693-9.

9. Wong RJ, Devaki P, Nguyen L, Cheung R. Nguyen MH Ethnic disparities and liver transplantation rates in hepatocellular carcinoma patients in the recent era: results from the Surveillance, Epidemiology, and End Results registry. Liver Transpl. 2014;20(5):528-35.

10. Feng K, Yan J, Li X, Xia F, Ma K, Wang S, et al. A randomized controlled trial of radiofrequency ablation and surgical resection in the treatment of small hepatocellular carcinoma. J Hepatol. 2012;57(4):794-802.

11. Cho YK, Kim JK, Kim WT, Chung JW. Hepatic resection versus radiofrequency ablation for very early stage hepatocellular carcinoma: a Markov model analysis. Hepatology. 2010;51(4):1284-90.

12. Wang $\mathrm{JH}$, Wang CC, Hung $\mathrm{CH}$, Chen CL. Lu SN Survival comparison between surgical resection and radiofrequency ablation for patients 
in BCLC very early/early stage hepatocellular carcinoma. J Hepatol. 2012;56(2):412-8.

13. Choi D, Lim HK, Rhim H, Kim YS, Lee WJ, Paik SW, et al. Percutaneous radiofrequency ablation for early-stage hepatocellular carcinoma as a first-line treatment: long-term results and prognostic factors in a large single-institution series. Eur Radiol. 2007;17(3):684-92.

14. Chan AC, Poon RT, Ng KK, Lo CM, Fan ST. Wong J Changing paradigm in the management of hepatocellular carcinoma improves the survival benefit of early detection by screening. Ann Surg. 2008:247(4):666-73.

15. Livraghi T, Meloni F, Di Stasi M, Rolle E, Solbiati L, Tinelli C, et al. Sustained complete response and complications rates after radiofrequency ablation of very early hepatocellular carcinoma in cirrhosis: Is resection still the treatment of choice? Hepatology. 2008;47(1):82-9.

16. Hung HH, Chiou YY, Hsia CY, Su CW, Chou YH, Chiang JH, et al. Survival rates are comparable after radiofrequency ablation or surgery in patients with small hepatocellular carcinomas. Clin Gastroenterol Hepatol. 2011;9(1):79-86

17. Chen MS, Li JQ, Zheng Y, Guo RP, Liang HH, Zhang YQ, et al. A prospective randomized trial comparing percutaneous local ablative therapy and partial hepatectomy for small hepatocellular carcinoma. Ann Surg. 2006;243(3):321-8.

18. N'Kontchou G, Mahamoudi A, Aout M, Ganne-Carrie N, Grando V, Coderc $E$, et al. Radiofrequency ablation of hepatocellular carcinoma: long-term results and prognostic factors in 235 Western patients with cirrhosis. Hepatology. 2009;50(5):1475-83.

19. Peng ZW, Lin XJ, Zhang YJ, Liang HH, Guo RP, Shi M, et al. Radiofrequency ablation versus hepatic resection for the treatment of hepatocellular carcinomas $2 \mathrm{~cm}$ or smaller: a retrospective comparative study. Radiology. 2012;262(3):1022-33.

20. Chu HH, Kim JH, Kim PN, Kim SY, Lim YS, Park SH et al. Surgical resection versus radiofrequency ablation very early-stage $\mathrm{HCC}(</=2 \mathrm{~cm}$ Single HCC): a propensity score analysis. Liver Int. 2019; 39(12):2397-407.

21. Liu P-H, Hsu C-Y, Hsia C-Y, Lee Y-H, Huang Y-H, Chiou Y-Y, et al. Surgical Resection Versus Radiofrequency Ablation for Single Hepatocellular Carcinoma $\leq 2 \mathrm{~cm}$ in a Propensity Score Model. Ann Surg. 2016;263(3):538-45.

22. Cucchetti A, Piscaglia F, Cescon M, Colecchia A, Ercolani G, Bolondi $\mathrm{L}$, et al. Cost-effectiveness of hepatic resection versus percutaneous radiofrequency ablation for early hepatocellular carcinoma. J Hepatol. 2013;59(2):300-7.

23. Zhou Y, Zhao Y, Li B, Xu D, Yin Z, Xie F, et al. Meta-analysis of radiofrequency ablation versus hepatic resection for small hepatocellular carcinoma. BMC Gastroenterol. 2010;10:78.

24. Li L, Zhang J, Liu X, Li X, Jiao B. Kang T Clinical outcomes of radiofrequency ablation and surgical resection for small hepatocellular carcinoma: a meta-analysis. J Gastroenterol Hepatol. 2012;27(1):51-8.

25. Huang J, Yan L, Cheng Z, Wu H, Du L, Wang J, et al. A randomized trial comparing radiofrequency ablation and surgical resection for HCC conforming to the Milan criteria. Ann Surg. 2010;252(6):903-12.
26. Ha TY, Hwang S, Lee YJ, Kim KH, Ko GY, li Gwon D, et al. Absence of Benefit of Transcatheter Arterial Chemoembolization (TACE) in patients with resectable solitary hepatocellular carcinoma. World J Surg. 2016;40(5):1200-10.

27. Pompili M, Saviano A, de Matthaeis N, Cucchetti A, Ardito F, Federico B, et al. Long-term effectiveness of resection and radiofrequency ablation for single hepatocellular carcinoma $\leq 3 \mathrm{~cm}$. Results of a multicenter Italian survey. J Hepatol. 2013;59(1):89-97.

28. Takayama T, Makuuchi M. Hasegawa K Single HCC smaller than $2 \mathrm{~cm}$ : surgery or ablation? Surgeon's perspective. J Hepatobiliary Pancreat Sci. 2010;17(4):422-4.

29. Tandon P. Garcia-Tsao G Prognostic indicators in hepatocellular carcinoma: a systematic review of 72 studies. Liver Int. 2009;29(4):502-10.

30. Arii S, Yamaoka Y, Futagawa S, Inoue K, Kobayashi K, Kojiro M, et al. Results of surgical and nonsurgical treatment for small-sized hepatocellular carcinomas: a retrospective and nationwide survey in Japan. The Liver Cancer Study Group of Japan. Hepatology. 2000;32(6):1224-9.

31. Lin CW, Chen YS, Lin CC, Lee PH, Lo GH, Hsu CC, et al. Autophagy-related gene LC3 expression in tumor and liver microenvironments significantly predicts recurrence of hepatocellular carcinoma after surgical resection. Clin Transl Gastroenterol. 2018;9(6):166.

32. Facciorusso A, Del Prete V, Antonino M, Crucinio N, Neve V, Di Leo A, et al. Post-recurrence survival in hepatocellular carcinoma after percutaneous radiofrequency ablation. Dig Liver Dis. 2014;46(11):1014-9.

33. Minami Y. Kudo M Adjuvant therapy after radical surgery for hepatocellular carcinoma: still an unmet need. Hepatobiliary Surg Nutr. 2019;8(4):414-6.

34. Bruix J, Takayama T, Mazzaferro V, Chau GY, Yang J, Kudo M, et al. Adjuvant sorafenib for hepatocellular carcinoma after resection or ablation (STORM): a phase 3, randomised, double-blind, placebo-controlled trial. Lancet Oncol. 2015;16(13):1344-54.

35. Facciorusso A, Del Prete V, Crucinio N, Muscatiello N, Carr Bl, Di Leo A, et al. Angiotensin receptor blockers improve survival outcomes after radiofrequency ablation in hepatocarcinoma patients. J Gastroenterol Hepatol. 2015;30(11):1643-50.

36. Cucchetti A, Trevisani F, Cappelli A, Mosconi C, Renzulli M, Pinna AD, et al. Cost-effectiveness of doxorubicin-eluting beads versus conventional trans-arterial chemo-embolization for hepatocellular carcinoma. Dig Liver Dis. 2016;48(7):798-805.

\section{Publisher's Note}

Springer Nature remains neutral with regard to jurisdictional claims in published maps and institutional affiliations.

Ready to submit your research? Choose BMC and benefit from

- fast, convenient online submission

- thorough peer review by experienced researchers in your field

- rapid publication on acceptance

- support for research data, including large and complex data types

- gold Open Access which fosters wider collaboration and increased citations

- maximum visibility for your research: over $100 \mathrm{M}$ website views per year

At BMC, research is always in progress.

Learn more biomedcentral.com/submissions 